\title{
Reflexivity as a Vital Skill for Future Researchers and Professionals
}

\author{
Anna Kimberley \\ Haaga-Helia UAS, Finland \\ University of Westminster, UK \\ anna.kimberley@gmail.com
}

\begin{abstract}
The emergence of a reflective paradigm in higher education in the last two decades, has been emphasised as a necessary skill both for future business professionals and researchers. The development of these skills should therefore be included in business school curricula. The ability to critically reflect has been identified as a crucial part of employability. This calls for developing pedagogical approaches that will stimulate students' critical thinking skills, encourage self-review as well as convey practice realities. This paper presents an application of such pedagogical methods applied in a set of course activities aimed specifically at developing reflexivity and self-efficacy of undergraduate business students, within the context of a university of applied sciences. It also demonstrates that the pedagogical solutions applied not only resulted in the desired learning outcomes, but also produced additional benefits to the students. A pedagogical approach was created and incorporated into one semester International Business Communication course taught to undergraduate international business students. It aimed at developing critical thinking skills, and reflexivity. It was incorporated in three activities: (1) introducing the students to the concept of reflexivity (reflecting on reflection), (2) writing reflectively about own cultural identity (reflection in action), (3) story writing and storytelling (reflecting on action). The methodological approach used was qualitative interpretation, and the method applied was narrative analysis of the data generated by reflective narratives created by the students. The findings showed that reflexivity was identified as a new concept, both necessary and helpful in self-development. Reflecting on one's own cultural identity created different types of awareness, which contributed to developing deeper knowledge about one's own cultural identity. Reflecting on story writing and storytelling showed the following learning benefits: discovering creative potential, as well as developing confidence in dealing with new, unexpected, and challenging situations. Moreover, the following additional learning benefits were identified: enhanced openness towards the immediate environment, improved understanding of otherness, and the applicability of the above skills for business professionals and researchers.
\end{abstract}

Keywords: Reflexivity, professional skills, qualitative research skills,

\section{Introduction}

In qualitative research reflexivity is considered one of the ways qualitative researchers should ensure rigor and quality in their work; it is also a vital part of ensuring trustworthiness (Teh \& Lek, 2018). Reflexivity as a process is introspection on the role of subjectivity in the research process. It is a continuous process of reflection by researchers on their values (Parahoo, 2006) and of recognising, examining, and understanding how their "social background, location and assumptions affect their research practice" (Hesse-Biber, 2007, p. 17). It can also be "some of the most challenging and important work in qualitative research" (Mitchell et al. 2018, p. 673). For a researcher, as well as the reader it is vital to describe contextual intersecting relationships (e.g., race, socioeconomic status, age, cultural background) between the participants and him/herself. Berger $(2015,220)$ claims that "Researchers need to increasingly focus on self-knowledge and sensitivity; better understand the role of the self in the creation of knowledge; carefully self-monitor the impact of their biases, beliefs, and personal experiences on their research; and maintain the balance between the personal and the universal".

Apart from its value in qualitative research Warton (2017, in Bolton 2018, 2) identified reflexivity as a vital skill that future professionals must develop, describing it as "a key element of employability in today's professions", and a professional imperative (McKay, 2008).

\section{Literature Review}

Dewey (1933) identified reflection as a different manner of thinking, in which reflection stemmed from doubt, hesitation or confusion triggered by a situation one experienced. According to Dewey, reflection begins with an experience and therefore facilitates learning from that experience, i.e., learning from doing. Dewey also claimed that reflective thinking moved people away from routine thinking/action (guided by tradition or external authority) and towards reflective action (involving careful, critical consideration of taken-for granted knowledge).

Dewey's concepts provided a basis for the concept of 'reflective practice' developed by Schön (1983). Adopting a metaphor of swampy lowlands Schön (1987) identified ways in which professionals could become aware of ISSN 1477-7029

CACPIL Reference this paper: Kimberley, A., 2021. Reflexivity as a Vital Skill for Future Researchers and Professionals. The Electronic Journal of Business Research Methods, 19(1), pp. 14-26, available online at www.ejbrm.com 
their implicit knowledge and learn from their experiences. Schön identified two types of reflection: reflectionon-action (after-the-event thinking) and reflection-in-action (thinking while doing).

The metaphor of swampy lowlands implies that students as learners and future practitioners are always immersed in their work environments where they gain experiences from which they learn. They learn by trial and error, which allows them freedom in trying to find diverse solutions to any given problem. Being a part of swampy lowlands requires road maps and paths. These Argyris and Schön (1974) call theories-of-use. Theoriesin-use, on the other hand, are what people do habitually and without much thought. In addition, people also employ espoused theories, which are what they believe they do. By critical reflection people can bring these two theories into congruence.

In addition to the above, there are other theories, frameworks and models that describe reflective processes. For example, the single loop (reflection) and double loop (reflection and reflexivity) theory proposed by Argyris and Schön (1974). Single loop develops awareness and calls for actions but leaves underlying deeper structures untouched. Similarly, Gibb's model (1998) focuses on a single event and adds thoughts, feelings and sensemaking. Johns (2013) developed a set of cues that focus on the description of an event, one's feelings, one's knowledge and one's personal values. Lastly, and similar to the concept of the double loop, Smith et al (2015) proposed a set of questions known as DATA (describe, analyze, theorize and act).

The above models are limited and thus present a danger that reflectors will limit their answers to the questions without developing their own narratives. Dewey's five-step model that allows for a wider perspective and openness are helpful, but as it examines only a personal experience, it does not accurately reflect reality.

Johns' Model of Structured Reflection (1994), used mostly in the health care field, offers a more reflexive approach. It is over-prescriptive and therefore has its disadvantages. It imposes an external framework and consequently leaves little scope for individuals to draw on their own intuitions, values and priorities. Johns has revised and developed his model, moving away from its prescriptive character in order to offer more holistic elements to encourage deeper reflection. Johns describes reflection as being "mindful of self" - whether during or after experience. He further claims that it is a "developmental process of paying attention to and learning through everyday experiences, with the goal of realizing a vision of practice as a lived reality." (Johns 2007).

I draw partly on Johns' reflective approach, but also incorporates Schön's (1987) concept of swampy lowlands and Brookfield's (2009) critical reflection that uncover and investigate the paradigmatic, prescriptive, and causal assumptions that inform how individuals practice and experience.

Students are often asked to provide feedback on the courses they complete. Although the feedback questions require the students to assess their own participation in the learning process, they do not contain a deep level of reflection. Moreover, learning diaries, which are often incorporated into courses, have a prescriptive approach whereby students are guided along throughout their reflection. Boud and Walker (1998) warn against such a 'manual' approach as it demands very little thinking, and it produces shallow reflection, and little learning for the student. Moreover, assessment of such a task is also problematic, given the personal nature of reflections.

I, therefore, conclude that neither providing feedback nor writing learning diaries provide a sufficient platform for students to develop reflexivity or boost their critical thinking. This paper contributes to filling the gap by proposing a pedagogical approach which by means of encouraging students to think critically and reflect, thus enhancing their reflective skills both as future practitioners and qualitative researchers.

Additionally, it strengthens their confidence and self-efficacy.

\section{Methodology}

The methodological approach stems from qualitative interpretation, and the method applied was narrative analysis of the data generated by the students' reflective narratives. A set of three activities was designed and incorporated into a one semester International Business Communication course. The course was taught to 120 first year BA international business students. I adopted constructivist perspective, as it emphasises the learners and their learning process first, downplaying my dominance as a teacher. This meant that my role as a teacher was to encourage the students to learn by doing, by interacting and exchanging knowledge with others, and 
through such learning experiences, develop and transform their views of themselves and reality. The students reflected on reality in conversations with others, and by the use of the language which came into being through discussions, argumentations and sharing views and opinions with others.

In order to ensure "qualitative rigour" (Gioia et al. 2013), while keeping an open mind, I adhered to a "systematic inductive approach to concept development" as devised by Gioia et al. $(2013,16)$. This approach allowed me to combine rigour and openness, as it assumed that the world is socially constructed by people who are "knowledgeable agents" (17).

In my analysis of the narratives I first attempted to elicit possible themes that might emerge. To better understand the way themes and categories differ I found the definition, proposed by Vaismoradi et al. (2016, 102 ) helpful. "Theme refers to a more implicit and abstract level, which requires interpretation. Category refers to explicit content of text and is a simple description of the participants' accounts". In the process of thematic analysis, particularly at the categorisation level, I found the model of three components: (i) origination, (ii) verification, (iii) nomination) proposed by Constas (1992) suitable.

Based on the model, I considered the students' narratives as primary sources of the categories. The verification stage supported the creation and application of the categories that emerged. In the last stage, nomination I finalised naming of the categories which were partly identical to the ones I identified in the origination stage. I saw categories as descriptors of themes.

The purpose of themes was to elicit the essence of the participant's experiences. I also understood themes as threads of underlying meaning with a common point of reference, with a high degree of generality. The meanings, as conveyed by the participants I implicitly discovered at the interpretative level. At this stage I followed the stages of theme development model proposed by Vaismoradi et al. (2016), which contains four stages: (i) initialisation, (ii) construction, (ii) rectification, (iiii) finalisation.

After reading and re-reading the reflective narratives I highlighted meaning units, coded them using the informant-centric codes, as my data analysis was driven by the voices of the students. Following Saldana (2009), I applied in vivo codes. In the first-order analysis I adhered very faithfully to the words and phrases used by the students. The codes were the words of the students themselves. The initial coding resulted in approximately 150-200 first-order codes per narrative. To reduce the number of codes I conducted a second phase of the analysis where I grouped these codes according to the similarities and relationships between them. This reduced the number of codes to about 50 per narrative. I was aware of the importance of my immersion in the data and its impact on the validity of the findings. I carried out additional reading of the narratives, and listed meaningful, recurrent ideas and key issues in data. Next, I tried to recognise explicit and implicit ideas in the narratives based on my own judgement.

At the construction phase I reflected on the process of organising codes. I compared them in terms of similarities and differences and clustered them into groups. In the rectification phase I checked and confirmed the clusters of codes in relation to the themes and categories yet again. I was aware that simultaneous immersion and distancing form the data may prevent me from taking a critical approach towards data analysis, thus hindering my ability to remain rigorous.

\section{The process}

The three activities aimed specifically at developing students' critical reflective skills. They were incorporated throughout the course and were connected to other components of the course. This connection was purposeful as it facilitated learning and developing other skills at the same time (public speaking, presenting, academic writing, academic analytical skills). The activities were grouped into three parts: (1) introducing the students to the concept of reflexivity (reflecting on reflection), (2) writing reflectively about one's own cultural identity (reflection in action), (3) writing reflectively (reflecting on action) on story writing and storytelling.

\subsubsection{Introduction to reflexivity, learning about and reflecting on reflection (activity 1)}

The primary aim of the first activity was to introduce the students to the concept of reflexivity. The secondary aims were: 1) to develop the students' familiarity with the style of academic writing (close critical reading of an academic article 'Reflecting on reflexivity' by Linda Finlay (2008) and 2) to teach the students to write an academic summary. 
The concept of the value of reflexivity as a professional and research skill was first introduced in an interactive lecture, during which the students were encouraged to ask questions and engage in a discussion. As part of the homework assignment the students were also asked to adopt what Finlay (2008) calls reflective practice as introspection, which invited students to engage in solitary self-dialogues in which they were asked to probe personal meanings and emotions. They expressed those dialogues by writing their own reflective narrative about the usefulness of reflection and reflexivity in learning, working, and carrying out research. To ensure as much freedom of expression as possible, there were no prescribed guiding questions, no length limitation, and no specific template to follow.

The assessment of this activity was based on the comprehensiveness of the academic summary and was graded on the scale 1-5. The personal reflection was not graded, but constructive feedback was provided.

\subsubsection{Culture and I, writing reflectively about own cultural identity, reflection in action (activity 2)}

The second activity introduced the students to the most salient theories in cultural studies. After an interactive lecture, as a follow-up the students were asked to write a reflective narrative: Culture and I. The students' task was to engage in intersubjective reflection (Finlay, 2008) which made them concentrate on relational cultural contexts, and the emergent and negotiated nature of their cultural encounters, as well as reflect on their own cultural identity. They were asked to tune into the cultural encounters and situations over the period of ten days. The students were asked to write their reflections in a form of notes, short paragraphs, separate sentences, or any other forms of communication, based on their observations and experiences. An electronic notebook was created to facilitate spontaneous writing using smartphones, tablets, etc. Similar to the previous activity, to ensure as much freedom of expression as possible there was neither a length limitation and nor a template to follow. Only a few general prompts and suggestions were given whose function was to guide the students. Here is an example of my instructions:

"This assignment is all about you and your cultural identity. Think about who you see yourself as interms of your cultural belonging/non belonging, what culture means to you, what you have experienced in different cross-cultural situations, and what you thought about it when it happened, how you felt, etc. The point of this assignment is to write thoughts, ideas, and reflections whenever something comes to your mind, every day, for example. Do not write it in one sitting. Real reflection happens all the time".

The assessment of this activity was based on the extent of reflexivity and was assessed as pass/needs improvement.

\subsubsection{Story writing, storytelling, writing reflective narratives, reflecting on action (activity 3)}

The third activity, story writing and storytelling, aimed at enhancing students' confidence in expressing themselves, giving and receiving feedback, developing analytical and critical skills, in the process of what I coined 'creative discovery'. The students' task was to write a story (individually) prompted by a traditional 6-step story model (character/setting, the goal the character wants to achieve, the hindering powers, the assisting powers, turning point, resolution). The students were asked to follow a set of six cards, each corresponding to the steps of the story model, i. e, the first card depicted the character and the setting, the second card depicted the goals of the character, etc. The images on the cards were often abstract and depicted images not directly associated with a character, or a setting. The students therefore were asked to let lose the reigns of their imagination and construct their stories however they wanted.

After completing the individual task writing of the stories, the students worked in groups of four, where they shared their stories with three other students, thus engaging in what Ghaye (2000) calls a 'reflective conversation'. Through mutual collaboration and conversation, a participatory, dialogical approach to reflective practice was achieved. Comments, peer feedback and discussion followed. The groups of four identified the themes of each other's stories. The themes were collected and analysed in a general discussion by the whole class. Lastly, as part of the homework, the students were asked to write reflective narratives.

Similar to the previous activities, to ensure as much freedom of expression as possible there was no length limitation and no template to follow. Only a few general prompts and suggestions were given. Here is an example of my instructions: "After the storytelling activity carried out in class, write a reflection about the activity. Remember that reflective writing is like having a dialogue with yourself. Think about the creative process you went through, the themes in your story, the other themes in the group wonder why you made a story with these themes and not others. What do they mean to you? Think about sharing the stories within the group, how did 
you feel doing this. What did you get out of this activity? Connect this activity to possible benefits you might have gained as a future businessperson and a researcher. Please do not write this reflection as simple answers to the topics above. They are only there to guide you in case you are lost. Write more!"

\section{Findings}

Introduction to reflexivity, reflecting on reflection (activity 1)

I was aware of some pedagogic concerns that teaching reflective practice entails. One of them was the developmental readiness of the students, and the extent to which forcing students to reflect may actually prove counterproductive. Some writers, for example Hobbs, 2007; Girffin, 2003, and Burrows, 1995 posit that learners need to be developmentally ready to engage in critical reflection and that some individuals may be incapable of doing so. The respective abilities of 'novices' and 'experts' are relevant here. There is evidence that novices, by definition lacking 'practical mastery', are inclined to follow models mechanically, and that such reliance on models lessens with experience (Gordon, 1984). As a result, the reflection that does occur can only be less effective.

The findings of the study support this claim. The majority of the students provided their reflections, but it was clear that they focused mainly on writing the summary, as this part of the assignment was graded. Their reflections were short and, in some cases, lacking.

Another relevant pedagogic concern was related to the compulsory element in reflective practice.When students are required to reflect through learning and assessment exercises, reflections can end up being superficial, strategic, and guarded. Where assessment lurks, any genuine, critical self-examination may well be discouraged. Even though the reflections in the study were not graded, less attention was paid to complete it in depth.

However, the reflective narratives of the students revealed themes that I placed into the following categories: Reflexivity, Writing academic summaries, and Reading academic articles. When talking about reflexivity itself the students described it as a collaborative activity and a vital skill.

"Reflective practice has been a vital aspect of formulating my perspectives and understanding howto improve my behaviour. "

"Personally, I see this concept as an invaluable skill in academic and occupational settings as well as in life as a whole. Everyone does it organically to some extent, and I feel as though it cannot be forced. The idea of a novice not branching away from technical procedures rings true in my own life. I have been in many situations, specifically in academic settings, where I was able to improvise and come up with solutions on the spot only after getting my footing in the environment. I have been able to translate this to other parts of my life as well. I think the fact that I tend to be creative and "wing-it" a lot is somewhat just a part of who I have always been naturally, but it was also nurtured by the academic settings in which I inadvertently used skills and concepts consistent with reflective practice".

The students also referred to reflexivity as an interesting subject and helpful in self-development. "Self-reflection is a very important 'skill' that everyone should be able to do. It is a good thing when you can look at your past and reflect on what you've done so that you can better yourself for the future."

"I have always found it very difficult to understand. Its thinking critically, but not exactly. So, what is it? I feel that this is partly because I'm just not that interested in the subject. This time I decided to give it a shot and see what happens. I read the article and found it difficult to understand. So, I read it many times over and I had to translate the words that were new to me. I started to realize why this subject is important and how it will affect your personal ability to grow as a professional. I was also taken by the fact that the author mentions that this subject really is complex and understanding it is hard. This gave me the opportunity to be more forgiving towards myself, for not trying hard enough to understand the definition of reflections." 
The students also mentioned learning aspects of the activity.

"I did not have any knowledge on this topic beforehand, so I do hope I have learned somehow more about reflecting."

"I do find that one's ability to able to use reflective practice can be really important and useful".

"Doing this assignment will help me in future to respect reflective practice and to try to take into consideration wider aspects like organizational, political and economic issues as well."

"Prior to reading this article, I would never have thought about the stages or types of reflection. I simply reflected by analysing what happened and then finding a solution. The article has broadened my knowledge of reflection and it offers some points that I will consider when reflecting in the future."

"This kind of practice will surely be helpful for future studies and work. I'm sure it is a vital skill to be able to point out the main subject from a conversation or from an article."

When referring to writing and reading academic article the students expressed difficulties, but also readiness to learn.

"The summary task was really hard because the academic text was very hard to understand. I'm sure, it will be easier when I get used to it."

"I have never written a summary before, but I think I did a good job as most (if not all) key ideasand subjects have been covered. It was good rehearsing the in-text referencing as it is something, I have previously never done either. All in all, I am happy with the result I have produced."

Table 1 illustrates the learning objectives set against the learning outcomes described by the themes identified by the students' narratives. It clearly shows that the learning objectives set by me in activity 1 were achieved. Even though the students found it difficult to read and understand the academic article, they submitted the completed assignment to the best of their abilities with enthusiasm and readiness to learn.

Table 1. Learning objectives vs outcomes, themes identified by the students

\section{REFLEXIVITY}

\begin{tabular}{|c|c|}
\hline LEARNING OBJECTIVES & OUTCOMES \\
\hline \multirow{3}{*}{$\begin{array}{l}\text { Introduction to the concept } \\
\text { of critical reflexivity }\end{array}$} & New subject \\
\hline & Vital skill \\
\hline & Collaborative activity \\
\hline \multirow[t]{2}{*}{ Application of critical skills } & Interesting subject \\
\hline & Helpful in self-development \\
\hline \multirow{2}{*}{\multicolumn{2}{|c|}{$\begin{array}{l}\text { Developing reading } \\
\text { and analytical skills of academic English }\end{array}$}} \\
\hline & \\
\hline Writing academic summaries & Difficult, challenging \\
\hline \multicolumn{2}{|l|}{ Writing critical reflective narratives } \\
\hline
\end{tabular}

4.1.4 Writing reflectively about one's own cultural identity, reflection in action (activity 2)

The analysis of the reflective narratives Culture and I revealed different themes identified by the students, depending on the students' national belonging and the nature and longevity of their residence in Finland. The themes were clustered into four categories: Awareness and Negativity (among Finnish students), Awareness and Openness (among foreigners: temporary sojourners), Awareness and Cultural Identity Work (among foreigners: permanent residents), Awareness and Ambiguity (among students with mixed cultural roots). 
The narratives of all the Finnish students showed enhanced awareness of their cultural identity characterised by negativity. However, the awareness also triggered varied thoughts and emotions depending on the students' previous experiences. Within the group of the Finnish students, the Finns permanently residing in Finland expressed, on the one hand anxiety and negative emotions about being Finnish, as well as a sense of not belonging in Finland. On the other hand, other students expressed strong adherence to being Finnish.

"I see myself very attached to my culture when I have guests. Today I had guests and, in my culture, especially in Carelian culture, it is very important to make your guests feel good and feed them well. I was able to see that in myself today."

"Finnish culture is a very prominent part of my cultural identity and thus when I go to the bus stop or metro stops I always smile at the fact that in Helsinki people don't really mind if they stand close to others or sit next to strangers, its normal here. Although, it is a ridiculous thing to do I do think it demonstrates how content we are with ourselves, we don't need or crave the closeness of others all the time and we are happy just being there and perhaps observing what is going on. I think it also shows trust is not just given but it has to be earned."

"I realised that Finnish customer service is so different compared to Finns' normal interaction and behavior. Finnish customer service is very open and happy and usually a salesperson is very talkative. Now that I think about it more, it feels odd."

"For a Finn, having your own space is important and it is really easy to see it in public places, such as trams, buses, gyms... I can also notice myself looking for a place that has less people around me".

"I've never felt myself as a true Finn. I've always felt a little more comfortable when talking to people with other cultural backgrounds, especially with Canadians. While I was admiring the scenery of small lakes and lush forests, and enjoying myself a Finnish craft beer, I thought to myself: This is one of the only few situations it feels good to be in Finland and being a Finn in general".

The Finnish students who had experiences of living outside of Finland expressed culture shock upon return. All the Finnish students pointed out a desire to travel abroad to learn and adopt different cultural habits. Most of the Finnish students, permanently residing in Finland, expressed negative emotions when referring to their cultural roots.

"I know it reads Finland in my passport but at certain age I tried to get rid of Finnish culture in me. I never felt I fit in Finnish society and always felt better abroad. Finnish culture seemed so dark, grim, and unhappy. At least in historical way. There were some Finnish culture traits that I adored or liked. The Finnish spirit, but then it all went down, and I don't see it anymore. "

Foreign students staying in Finland on a temporary basis (temporary sojourners) i.e. exchange students expressed strong cultural awareness characterised by openness. They were very curious about Finnish culture, they often made comparisons between habits and customs in their own cultures and Finnish culture, and often expressed preference of Finnish ways. They were eager to learn new Finnish ways. In many cases they identified experiencing culture shock especially regarding education. Here are excerpts from the narratives of exchange students. Exchange student from Austria:

"The Finns are never saying anything, and they are also not staring at me. They give you the privacy needed because they do that here in Finland. I have to say, it is really nice to have this amount of privacy in the gym here but sometimes it is also a bit boring because no one is ever having a conversation with you".

Exchange student from Russia:

"I personally think that in Finland is well-being on such a high level, that Finns do not appreciate it. Almost every day in the school there are a few Finnish classmates, who complain about almost everything. It annoys me so much, because I think that student at the university should have another attitude."

"Sometimes I am thinking about that, that maybe the school should have had more difficult entrance exams cause some people just should not be there. I do not feel comfortable if I say that it is too easy; 
everyone stares at me because of what I said. There is lack of motivation among students, I think that is because of the fact, that the majority cannot imagine worse school system or condition of life. I can".

Exchange student from Slovakia:

"I recognised that the young people here are divided into 2 groups. The first one is, that the people are engaged or in serious relationship, and the second one is the extreme opposite, that they do want just the freedom and time for themselves. I wonder why it is so. In Slovakia, the majority of people in my age want to have the proper relationships, because they know that as they are aging it is more difficult to find someone who fits. Here the people think more about today, not future. Have no plans, goals, dreams".

Foreign students residing in Finland permanently, expressed cultural awareness characterised by cultural identity work. Their narratives revealed the following themes: amazement and frustration, adherence to and pride in their own culture, comparisons between their native cultures and Finland, attempts to combine both cultures.

"My culture is a combination of two different cultures, Finnish and Filipino. My values are a combination of the two, but I do not agree with all values of both cultures".

"Last 9 years I have been living in Finland and become Finn by passport. I don't feel myself belonging to modern Ukrainians and still cannot belong to Finns. My identity formed, by my past does not exist anymore. Currently I am on crossroad."

The final group of students, with mixed cultural identities. Their narratives expressed cultural awareness characterized by awareness and ambiguity, and revealed the following themes: tension and frustration (who am I?), a sense of being located in-between, a sense of necessity to reject one culture to create space for another (preferred) culture, and lastly, disappointment and confusion.

"I had an identity crisis until a family friend asked me: Where do you think you are from? It took me a while to formulate my answer, but I concluded that, I am mentally Japanese and physically Finnish. Specifically, I am mentally Japanese since I grew up with Japanese values, morals and mental behavior. On the other hand, I am physically Finnish since I use Finnish in my daily physical life. "

"Sometimes though, as I rely too much on being aware of where my heritage comes from, I feel that I easily loose grip of who I truly am, instead of where my heritage comes from. Even though cultural heritage is a big part of one's identity, I feel as if it may also hinder you from grasping who you are when all those stories of cultural diversity is stripped away?"

Table 2: Learning objectives vs. outcomes; themes based on students' reflections

\title{
CULTURE AND I
}

\section{LEARNING OBJECTIVES}

\section{OUTCOMES}

\author{
Becoming culturally self-aware \\ Becoming culturally aware of others \\ Developing cultural understanding \\ of self and others \\ Learning the concepts of cultural studies \\ Reflecting critically on own cultural identity
}

Awareness and ambiguity
Awareness and negativity
Awareness and openness
Awareness and identity work
"Connecting theory to me"
"Good to think of who one is"

Awareness and ambiguity

d negativity

\subsubsection{Story writing, storytelling, writing reflectively, reflecting on action (activity 2)}

The reflective narratives created by the students after the class activity revealed an abundance of themes. They were aggregated into the following categories: Unconventional Learning, Creativity, Surprise and Discovery, Expressing True Self and Knowing Others. Additionally, the students made clear connections of storytelling activity to business life (Storytelling and Business). 
The following excerpts from the students' reflective narratives highlight the reflections on the unconventional way of learning and its connection to enhancing creativity and building confidence.

"I really enjoyed myself during the storytelling activity and I had a lot of fun doing this kind of essay writing. It really brought out my creative character and made me feel free to let my own thoughts and feelings out. It was very interesting to hear how the others solved this task and overall even though first I did not understand why this would help us, now I do".

"This assignment gave me more courage to read out texts written by me. Also, it was very different to other assignments we have had so it was great fun. In business life it must also be crucial to have imagination and courage, and I think these are the things I got out of this activity".

"I enjoyed this practice and hope to see more this kind of work. I can implement these to my future and to business too. You have to be very creative in marketing for example, but it goes to all business in general. How you write your CV, how you tell your personal story in interview etc. It was fun assignment, something to deviate from the norm".

The narratives also showed that the students felt encouraged to express themselves both by writing their stories and sharing them with their peers.

"I was confident about sharing my story, because we had to write it quick and I think it is not a problem to me to write stories. Of course, I was not $100 \%$ confident, but I got it trough. I did not really understand the meaning of this exercise, but it helped me to use my imagination and to be brave enough to share my story to others, even if it would be silly".

"Even though I have confidence, this situation demonstrates that I still have a long way to go before I can present any ideas with no fears".

"This session taught me to be brave and show my work to others no matter how silly I think it is because in the end of the day the people in my group also had an equally silly but thrilling story as well. Although sceptical at first on the importance of the story telling idea in the end I learnt a great deal on how even silly things have a meaning behind them and how you interpret it is one hundred percent on you without any limits and judgment. It will help me in the future to envision anything even thought it might not make sense in the beginning".

Expressing True Self and Knowing Others

"Business can be strenuous in whatever field you are specialising, but if you focus on releasing your emotions, whether it be through storytelling or reflective practice, a person is able to lighten their emotional load. Storytelling can be a 'less direct' approach to reflective writing, because instead of directly writing about your feelings, you are indirectly expression your emotions".

"This is also an invaluable tool in business because getting multiple perspectives on a problem can open many paths to a solution instead of just one".

"It showed me that lots of people have similarities even when they come from different cultures and backgrounds. By searching for those similarities, I should be able to form effective partnerships and teams in business which can hopefully propel me to success".

Creativity, Surprise and Discovery

"When I saw the cards I got handed out, first I thought it would be almost impossible for me to connect them into a story. But as I started writing, after a while I got into that magical world of the cards and I enjoyed it a lot".

"My story had a romantic way to it which I feel like reflects my personality. The colors and images really inspired my story. It was hard sometimes to connect some cards into the story, but I feel like it turned out well. When we were reading our stories in the small groups, I was so surprised". 
"When I started, suddenly I could not stop writing. I wanted to have the story with deep meaning and interesting characters. It took me some time because my story was a bit long, but that did not bother me because I liked the process".

"This activity enhanced my imagination and creativity".

\subsubsection{Storytelling and Business}

The narratives demonstrated students making connections between storytelling and its value and application to situations in a business environment.

"I think storytelling is a very important part of business. You need to be able to present yourself, your company and the products you are selling to an audience and storytelling is a great way to do that. I want to specialise in marketing as a part of my degree, so I feel like the skill of storytelling will be even more important than it would be if I majored in finance. This might help me in marketing. To create a story. A word you want to spread to the world or a thing which makes people think".

"I can see that storytelling has very much to do with business. People in different roles need the skill to create a good story to support for example a product. With a good story it is possible to stand out from the others. People in marketing, sales, entrepreneurs, and so on can use storytelling in their lives and careers".

"For a businessperson it is important to be creative and sometimes the creativity has to come fast and I think that this activity was good for practicing that".

Through the activity of story writing and storytelling, the students experienced an opportunity to overcome the initial confusion when faced with the task of creating coherent stories based on abstract images. As they began the creative process of writing they realised that the task became not only easy but also, enjoyable. Enjoyment triggered creativity, and as the stories emerged the realisation of completing a seemingly impossible task created additional enjoyment.

The initial confusion by the requirements of the task was overcome by the process of writing and was superseded by discovery that, just by doing, one can overcome initial difficulties. This was followed by a discovery of the value of the assignment.

The non-judgmental environment of small groups in which the stories were shared, as well as positive peer feedback not only encouraged self-expression, but also created an opportunity to get to know one's self and others in a meaningful way. Table 3 illustrates the learning objectives vs outcomes.

Table 3: Learning objectives vs. outcomes; based on students' reflections

\section{STORYWRITING, STORYTELLING}

LEARNING OBJECTIVES $\quad$ OUTCOMES

\section{Encouraging creativity}

and innovative thinking

Developing critical thinking

Strengthening students' writing skills

Enhancing listening skills

Developing communication

and argumentation skills

Developing listening skills
Confusion, surprise, discovery

Building confidence

Expressing True Self and Knowing Others

by encouraging self-expression 


\section{Discussion}

During participation in the activities in class and when reflecting on them afterwards the students went through a developmental learning process during which they were asked to pay attention to their reactions, analyse and reflect on them in order to realise their part in the lived reality as well as their learning process (Johns, 2007). The activities created situations where the students investigated and reflected on their personal paradigmatic assumptions about themselves and others. By carrying out a critical reflection (Brookfield, 2009), they discovered, scrutinised and questioned the assumptions that informed the way they experienced, perceived, and practiced.

Dewey's (1933) concept of reflection as a manner of thinking that stems from doubt, confusion and hesitation resonated in the data obtained from the reflective narratives of the students. Faced with the task of creating a coherent story out of abstract and confusing images triggered a reaction and a sense of confusion (How can I do this? Why am I doing this in a business communication course?), followed by doubt (I do not think I can do it. I cannot write a story), and fear (What if I cannot do it?). All these reactions were triggered by a situation in which the students faced an experience of dealing with seemingly impossible tasks.

Despite the initial confusion, doubt, hesitation, and fear, prompted by the requirements of completing the storytelling assignment on time, the students begun the writing process. The fear they experienced at the beginning was overcome and turned into a positive, creative process as the stories begun taking shape on paper, and the unconscious learning process begun. The creative pull that the assignment called for, cleared the confusion, dispersed the doubts, and encouraged the students to overcome the fear.

They learned by doing and reflecting on the activity afterward. Their learning was not limited only to learning about the actual activity they took part in, but also about themselves as actors performing in that activity. They experienced another stage in the learning process: discovery and surprise. They discovered the potential of innovative ways of dealing with a difficult task and experienced a sense of surprise when they were able to perform successfully.

When reflecting on their own cultural identities the students experienced being lost in the swampy lowlands Schön (1987) where they became aware of their implicit knowledge of themselves, and where they were encouraged to reflect more deeply, which Johns (2007) describes as being about "mindful of self" .

The students went through a developmental learning process that lasted ten days. During this period, they were asked to pay attention to their everyday experiences, analyse and reflect on them to realise their part in the lived reality (Johns, 2007). They were also in a situation where they had to investigate and reflect on their personal paradigmatic assumptions about themselves and others. By carrying out a critical reflection (Brookfield, 2009), they discovered the assumptions that inform the way they experience perceive and practice.

Finally, the element of discovery and surprise of learning in a different and unconventional way moved the students' thinking away from routine and conventional ways of learning where the external authority of a teacher guides them in their learning. Instead they experienced deep levels of learning in a relaxed and fun atmosphere, where there were no wrong or right answers, and where any students' input was accepted and acknowledged as valuable, both by the peers and the teacher.

\section{Conclusions}

The three learning activities incorporated into International Business Communication were designed to answer the need to develop critical reflexivity skills of undergraduate business students, to prepare them for the demands of future working life as researchers and businesspersons.

The reflective narratives showed that storytelling proved to be an unconventional and innovative means to learn and discover. Whilst having fun the students developed and learned skills that were identified as crucial for future business professionals and researchers. These skills were critical analytical skills, empathy (self- and others awareness), awareness of the general environment, confidence in tackling challenging and unexpected tasks, creative problem solving, discovering, and believing in one's own creative potential. These skills significantly contribute to strengthening the reflexivity skills. 
I see it as the first step in further development of deeper analytical and critical skills, cultural awareness, communication confidence and self-efficacy of young graduates as they face real-life practical situations in business as well as in academia.

\section{Acknowledgements}

The author wishes to thank Dominika B. Kimberley for proofreading this paper.

\section{References}

Argyris, M. and Schön, D. (1974) Theory in Practice: Increasing Professional Effectiveness. San Francisco, CA: Jossey-Bass. Bandura, A. (1971) Social Learning Theory. General Learning Press.

Berger, R. (2015)" Now I see it, now I don't: Researcher's position and reflexivity in qualitative research". Qualitative Research, Vol 15, No.2 pp 219-234. doi:10.1177/1468794112468475

Boud, D. and Walker, D. (1998) "Promoting Reflection in Professional Courses: The Challenge of Context", Studies in Higher Education, Vol 23, No. 2.

Brink, K., E., and Costigan, R. (2015) "Oral Communication Skills: Are the Priorities of the Workplace and AACSB-Accredited Business Programs Aligned?", Academy of Management Learning and Education, Vol 14, No. 2.

Bolton, G., and Delderfield, R. (2018) Reflective Practice, Writing and Professional Development, Sage Publishing.

Brookfield, S. D. (2009) Engaging Critical Reflection in Corporate America, in Practice: Insights from Community, Workplace and higher Education. San Francisco, CA: Jossey-Bass.

Burrows, D.E. (1995) "The nurse teacher's role in the promotion of reflective practice", Nurse Education Today, Vol 15, pp 346-350.

Cavanagh, T. M., Leeds, C. and Peters, J. M. (2019) “Increasing Oral Communication Self-Efficacy Improves Oral Communication and General Academic Performance", Business and Communication Professional Quarterly. URL: https://doi.org/10.1177\%2F2329490619853242

Clandinin, D. J., Lessard, S., and Caine, V. (2012) Reverberations of Narrative Inquiry, how resonant echoes of an inquiry with early school leavers shaped further inquiries. Centre for Research for Teacher Education and Development, University of Alberta (Edmonton/Canada).

Constas, M. A. (1992) Qualitative analysis as a public event: the documentation of category development procedures. American Educational Research Journal. Vol 29, No 2, pp 253-266. URL: http://dx.doi.org/10.102/00028312029002253

D'Aloisio, A. (2006) "Motivating Students Through Awareness of the Natural Correlation Between College Learning and Corporate Work Setting “, College Teaching, Vol 54, No.2 URL: https://doi.org/10.3200/CTCH.54.2.225-230

Dewey, J. (1993) How We Think: A Restatement of Reflective Thinking in the Educative Process. Boston, MA: DC Heath \& Co.

Dodgson, J. D., (2019) "Reflexivity in Qualitative Research", Journal of Human Lactation, Vol 35, No. 2, pp 220-222. URL: sagepub.com/journals-permissions DOI: 10.1177/0890334419830990 journals.sagepub.com/home/jhl

Du-Babcock, B. (2006) "Teaching Business Communication Past, Present, and Future". Journal of Business Communication, Vol 43, No.3, pp 253-264.

Finlay, L. (2008)" Reflecting on 'Reflective practice' A discussion paper prepared for PBPL CETL", (www.open.ac.uk/pbpl.)

Gibbs, G. (1998) Learning by Doing: A Guide to Teaching and Learning Methods. London: FEU.

Gibbs, G (1988) Learning by doing: a guide to teaching and learning methods. Oxford: Further Education Unit, Oxford Polytechnic.

Gioia, D. A., Corley, K. G. and Hamilton, A. (2013) “Seeking Qualitative Rigor in Inductive Research", Organizational Research Methods, Vol 16, No. 1, pp 15-31.

Ghaye, T. (2000) "Into the reflective mode: bridging the stagnant moat", Reflective Practice, Vol 1, No. 1, pp 5-9.

Griffin, M. (2003) "Using critical incidents to promote and assess reflective thinking in preservice teachers". Reflective Practice, 4 (2), 207-220.

Hesse-Biber, S. N. (2007) Handbook of feminist research: Theory and praxis. Thousand Oaks, CA: Sage Publications Inc.

Hesse-Biber, S. N. and Piatelli, D. (2007) Holistic reflexivity. In S. N. Hesse-Biber (Ed.), Handbook of feminist research: Theory and praxis (pp. 493-514). Thousand Oaks, CA: Sage Publications Inc.

Hobbs, V. (2007) "Faking it or hating it: can reflective practice be forced?" Reflective Practice, Vol 8, No. 3, pp 405-417.

Johns, C. (2013). Becoming a Reflective Practitioner: $4^{\text {th }}$ edn. Oxford: Wiley Blackwell.

McKay, E.A. (2008, Forthcoming) Reflective practice: doing, being and becoming a reflective practitioner. Skills for Practice in Occupational Therapy. Oxford: Elsevier Ltd.

Ortiz, J. (2016) "New graduate nurses' experiences about lack of professional confidence". Nurse Education in Practice. Vol 19. URL: https://doi.org/10.1016/j.nepr.2016.04.001

Palaganas, E. C., Sanchez Visitacion, M., C. and Caricativo, R. D. (2017) "Reflexivity in Qualitative Research: A Journey of Learning". The Qualitative report, Vol 22, No. 2.

Parahoo, K. (2006) Nursing research principles, processes, and issues (2nd ed.). Hampshire, UK: Palgrave Macmillan.

Schön, D. A. (1987) Educating the Reflective Practitioner, San Francisco, CA: Jossey-Bass.

Smith, T. L., Barlow, P. B., Peters, J. M., and Skolits, G. J. (2015) “Demystifying Reflective practice: using the DATA model to Enhance Evaluators' Professional Activities". Evaluation and Program Planning, Vol 52. 
Smith, J. A. and Osborn, M. (2004) Interpretative Phenomenological Analysis. URL: https://doi.org/10.1002/9780470776278.ch10

Teh, Y. Y. and Lek, E. (2018) "Culture and reflexivity: Systemic journeys with a British Chinese family". Journal of Family Therapy, Vol 40, pp 520-536. doi:10.1111/1467-6427.12205

Tucker, M., J. and McCarthy, A. M. (2001) "Presentation Self-Efficacy: Increasing Communication Skills Through ServiceLearning", Journal of Managerial Issues, Vol 13, No. 2.

Vaismoradi, M., Jones, J. Turunen, H., Snelgrove, S. (2016) Theme development in qualitative content analysis and thematic analysis, Journal of Nursing Education and Practice, Vol 6, No.5.

Wharton, S. (2017) "Reflection in university and the employability agenda: a discourse analysis case study". Reflective Practice, Vol 18, No. 4, pp 567-79. 